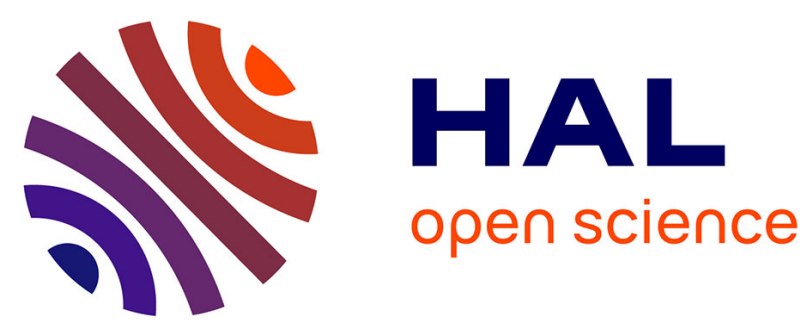

\title{
Array-CGH analysis indicates a high prevalence of genomic rearrangements in holoprosencephaly: an updated map of candidate loci.
}

Claude Bendavid, Lucie Rochard, Christèle Dubourg, Jonathan Seguin, Isabelle Gicquel, Laurent Pasquier, Jaqueline Vigneron, Annie Laquerrière, Pascale Marcorelles, Corinne Jeanne-Pasquier, et al.

\section{To cite this version:}

Claude Bendavid, Lucie Rochard, Christèle Dubourg, Jonathan Seguin, Isabelle Gicquel, et al.. ArrayCGH analysis indicates a high prevalence of genomic rearrangements in holoprosencephaly: an updated map of candidate loci.. Human Mutation, 2009, 30 (8), pp.1175-82. 10.1002/humu.21016 . inserm00404487

\section{HAL Id: inserm-00404487 https://www.hal.inserm.fr/inserm-00404487}

Submitted on 3 Oct 2014

HAL is a multi-disciplinary open access archive for the deposit and dissemination of scientific research documents, whether they are published or not. The documents may come from teaching and research institutions in France or abroad, or from public or private research centers.
L'archive ouverte pluridisciplinaire HAL, est destinée au dépôt et à la diffusion de documents scientifiques de niveau recherche, publiés ou non, émanant des établissements d'enseignement et de recherche français ou étrangers, des laboratoires publics ou privés. 


\section{Human Mutation}

WILEY

Array-CGH analysis indicates a high prevalence of genomic rearrangements in Holoprosencephaly: an updated map of HPE candidate loci.

\begin{tabular}{|c|c|}
\hline Journal: & Human Mutation \\
\hline Manuscript ID: & draft \\
\hline Wiley - Manuscript type: & Research Article \\
\hline Date Submitted by the Author: & $\mathrm{n} / \mathrm{a}$ \\
\hline Complete List of Authors: & 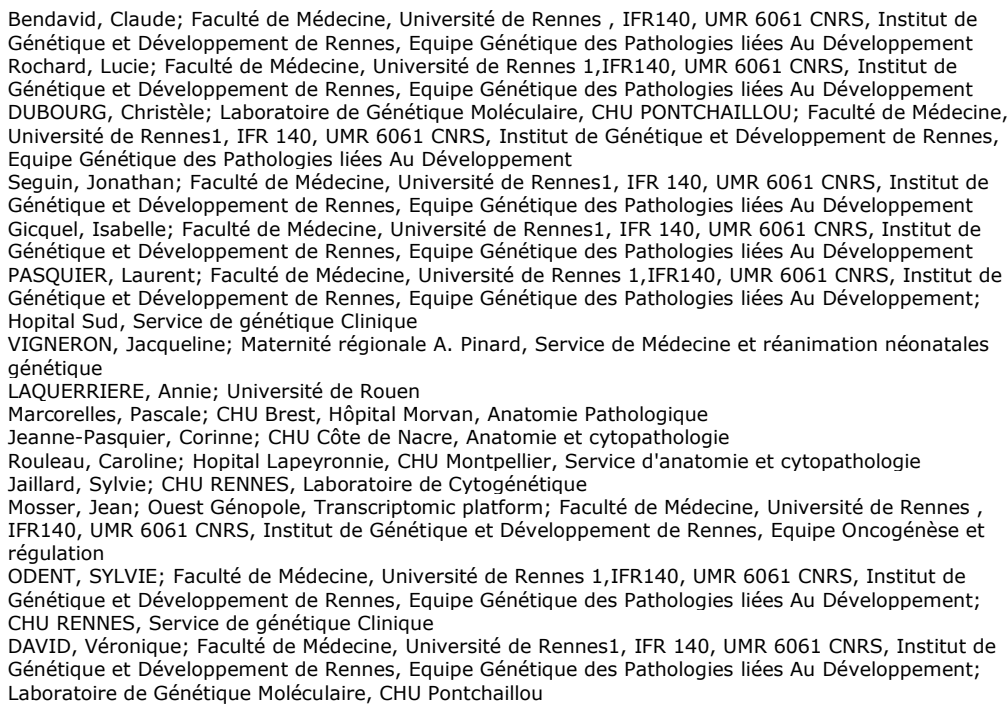 \\
\hline Key Words: & holoprosencephaly, CGH array, rearrangements, candidate loci \\
\hline
\end{tabular}

\section{S) ScholaroNE}




\section{Array-CGH analysis indicates a high prevalence of genomic rearrangements in Holoprosencephaly: an updated map of HPE candidate loci.}

\section{Acknowledgments}

This work was funded by PHRC interrégional 2004, GIS maladies rares (GISMR0701), FMO (Fédération des Maladies Orphelines).

We particularly thank the SOFFOET for providing several Fetus cases with complete anatomical description of cerebral defects, all clinicians who referred HPE cases and all families for giving their consent to this study. 


\section{ABSTRACT}

Holoprosencephaly (HPE) is the most frequent congenital malformation of the brain. Aetiology includes karyotype anomalies, environmental factors and genic forms that can be syndromic or isolated. Non-random structural chromosomal anomalies previously compiled from chromosomal HPE predicted at least 12 different HPE loci. To date, eight HPE genes have been identified from recurrent chromosomal rearrangements or from the sequencing of genes from Nodal and $\mathrm{SHH}$ pathways.

Our cohort of isolated HPE presents a high genetic heterogeneity. Point mutations were found in SHH, ZIC2, SIX3 and TGIF genes in about $20 \%$ of cases (with $10 \%$ in $S H H$ ). Submicroscopic deletions in these same genes were found in $7.5 \%$ and $4.4 \%$ presented with other subtelomeric gain or losses. Consequently molecular basis of HPE remains unknown in $70 \%$ of our cohort.

In order to detect new HPE candidate genes, we used array-CGH to refine the previous karyotype based HPE loci map. We analysed 111 HPE patients with high performance Agilent arrays made of $44 \mathrm{~K}$ or $244 \mathrm{~K}$ oligonucleotidic probes and found that 28 presented with submicroscopic anomalies involving known or new potential HPE loci located on different chromosomes but with poor redundancy. We observed 14 isolated deletions, 9 isolated duplications and 5 associated genomic losses and gains. Compiling these new data with frequencies of deletions in known HPE genes and of subtelomeric anomalies, we give evidence that microrearrangements could be a major molecular mechanism in HPE. Additionally, this study opens new insights on HPE candidate genes identification giving an updated HPE candidate loci map. 


\section{INTRODUCTION}

Holoprosencephaly (HPE; MIM 236100) is the most common forebrain developmental anomaly in humans, resulting from a complete or partial failure of cleavage of the forebrain during development. The clinical spectrum ranges from alobar HPE (absent interhemispheric fissure) to semilobar (posterior midline separation) and lobar HPE (continuity only across the frontal cortex) generally associated with facial anomalies. HPE is a severe pathology, associated with mental retardation in all affected live newborns, with poor or symptomatic treatment (Cohen, 2006). The genetic counselling in HPE families is very complex due to the extreme phenotypical variability, the genetic heterogeneity, and a high recurrence risk $(13 \%)$ in apparently sporadic cases. Chronologically, non-random structural chromosomal anomalies previously compiled from chromosomal HPE predicted at least 12 different HPE loci, and out of these 12 loci, eight genes have been really implicated in HPE with mutations found in isolated HPE: Sonic hedgehog (SHH; 7q36; HPE3)(Belloni, et al., 1996; Roessler, et al., 1996)], ZIC2 (13q32; HPE5)(Brown, et al., 1998), SIX3 (2p21; HPE2)(Wallis and Muenke, 1999), TGIF (18p11.3; HPE4)(Gripp, et al., 2000), PATCHED1 (9q22)(Ming and Muenke, 2002), TDGF1 (3p21.31)(de la Cruz, et al., 2002), FAST1 (8q34) (Ouspenskaia, et al., 2002) and GLI2 (2q24)(Roessler and Muenke, 2003). In total, these actors play a role either in the SHH pathway, or in the Nodal/Transforming Growth Factor beta (TGF $\beta$ ) pathway, or as transcription factors. Point mutations in the four major genes, SHH, ZIC2, SIX3 and TGIF, were identified in $20 \%$ of our HPE patients. Among these genes, SHH appears to be the major one accounting for $50 \%$ of the identified mutations (Dubourg, et al., 2004).

Animal studies and rare human cases showed that double heterozygous mutations could be involved in HPE phenotype, introducing the multi-hit hypothesis in this developmental disorder (Ming and Muenke, 2002). This hypothesis helped in the understanding of the variable penetrance of familial mutations in the disease and led us to systematically screen the four genes, even if one mutation was initially found in the first sequenced gene. Additional work is focusing on environmental factors including low cholesterol levels (Edison, et al., 2007).

Since 2003, we also screened these genes for microrearrangements and proved for the first time the implication of gene deletions in $7.5 \%$ in holoprosencephaly $(3.2 \%$ in 
SHH, $2 \%$ in ZIC2, $1.6 \%$ in SIX3 and $0.65 \%$ in TGIF) (Bendavid, et al., 2006a; Bendavid, et al., 2006b). When comparing the combined mutation and deletion results observed in the foetus cohort and in the live-born children, the total proportions of gene anomalies are close ( $28 \%$ and $24 \%$ respectively), but the rate of point mutations is much higher in live born children than in foetuses $(23 \%$ versus $14 \%)$ whereas submicroscopic deletions, which represent gross alterations, occur more frequently in foetuses (10\% versus $5 \%$ ) who generally have a more severe phenotype.

Because of the HPE clinical and genetic heterogeneity, and the lack of informative families, a classical positional cloning strategy based on genome wide scan is not possible. Consequently, we were led to develop a strategy based on molecular biology and cytogenetics to identify candidate regions and thus candidate genes. This approach will complete the initial karyotype based study of recurrent chromosomal abnormalities which led to the identification of the first HPE genes (Belloni, et al., 1996) and HPE loci map (Roessler and Muenke, 1998).

After screening of microdeletions or mutations in known HPE genes with QMPSF/MLPA or DHPLC plus sequencing respectively, we searched for submicroscopic rearrangements in subtelomeric chromosomal regions using the Multiplex Ligation Probe Amplification (MLPA) method (Hogervorst, et al., 2003). Indeed, subtelomeric aberrations were detected in $4,4 \%$ of our HPE patients with no known anomaly, showing either a single anomaly or an association between a deletion and a gain, these rearrangements were very heterogeneous, encompassing 10 different subtelomeric regions. Some targeted regions known to be implicated in HPE (7q encompassing the SHH gene, 18p encompassing the TGIF gene, 21q including a candidate gene, LSS (Lanosterol Synthase)), but also new regions (1p, $5 q, 7 p, 8 p, 9 q, 17 q, 18 q$ and 22q) were identified. Several samples, mainly foetal ones, consisted of an association between a duplication and a deletion in two chromosomal subtelomeres like (dup7pter; del7qter) or (dup20pter; del21qter). Moreover, rearrangements presented by foetuses generally implied known HPE loci, while those observed in live children encompassed regions not previously described (Bendavid, et al., 2007). But, even if we compile these large deletions, point mutations and deletions in the known genes, the combined rate of patients with identified molecular basis only reaches $30 \%$, so more than $70 \%$ of the cases remain 
unexplained, suggesting the involvement of many other genes in HPE (Dubourg, et al., 2007) and/or non genetic factors.

The previous data showed the growing importance of microrearrangements in a complex genetic disease where mutations in the different genes have a variable penetrance and may need a second genetic event to give the disease. In order to identify new candidate loci and thus novel candidate genes, we decided to perform a genome wide screening for submicroscopic anomalies on isolated HPE patients, using Agilent array-CGH technology. We first tested the technique on 10 patients with known alterations in SHH, TGIF, ZIC2, SIX3 or subtelomeres in order to better define the size of the rearrangement and the breakpoints. Then 111 samples (64 fetuses and 47 live-born children), with no known karyotypes alterations, were hybridized. We chose these patients with no regard to their mutational status for the main HPE genes, resulting in that $18 \%$ of this group were carrying a mutation.

Confirming the growing importance of micro rearrangements, this study showed up an impressive rate of 28 patients among 111 with submicroscopic chromosomal anomalies. These defects involved known or new potential HPE loci located on different chromosomes but with poor redundancy. Added to the previous microdeletion findings in known HPE genes and subtelomeres, our data showed that microrearrangements could be the major molecular mechanism in HPE and strongly reinforce the multigenic origin in this developmental disorder.

\section{MATERIAL AND METHODS}

\section{Patients and controls}

The cohort consisted in 9 patients presenting with a known deletion already detected by qPCR or QMPSF in HPE genes (SHH, TGIF, ZIC2 and SIX3) or telomeric rearrangements shown by MLPA experiments and 111 HPE patients (64 fetuses and 47 live-born children) with normal karyotype. Out of this whole cohort, all foetuses had severe HPE (central nervous system (CNS) findings consistent with HPE) whereas 15 live-borns had severe HPE and 32 had a spectrum of HPE microsigns (midline defect without cerebral malformation, including facial clefting, single central maxillary incisor, hypotelorism). 
Twenty patients with already known point mutations in the four HPE genes were also included, 20 of them with an inherited mutation and a severe phenotype whereas the transmitting parent had a microform.

For only 21 cases with positive $\mathrm{CGH}$ result, we had both maternal and paternal DNA that could be investigated by array-CGH, MLPA or quantitative PCR to confirm de novo alterations.

In order to simplify the interpretation of the results and better characterize CNVs, we used genomic DNA from one well-characterized normal male 46,XY and 1 wellcharacterized normal female $46, \mathrm{XX}$ as control. These two controls were regular blood donors that gave consent (to Etablissement Français du Sang) to use anonymously their DNA for diagnosis or research purposes.

This study was approved by the Institutional Review Board, and parents of all participants gave their informed consent.

\section{Comparative Genomic Hybridization study}

Briefly, for live-born children, genomic DNA was extracted from peripheral whole blood by the Flexigene DNA kit from QIAGEN. For foetuses, DNA was extracted from tissues or cultured amniotic cells, using the QIAamp DNA minikit from QIAGEN. DNA concentration was determined using a NanoDrop Spectrophotometer (NanoDrop Technologies, Inc., Wilmington, DE).

Array-CGH analysis can be hampered by the large DNA input requirement: a minimum of $0.5 \mu \mathrm{g}$ per sample are needed to process one array-CGH. Most of our samples were extracted from foetuses, and only a small amount of DNA is often available. So, when necessary, DNA samples were amplified using a whole genome amplification method. In this case, control DNA was also amplified in order not to cohybridize a native DNA from a control with an amplified DNA from a patient.

DNA amplification 
DNA samples were amplified using the GenomePlex WGA kit (Sigma product code WGA2) according to the protocol provided by Sigma. The amount of DNA input into WGA reactions was $50 \mathrm{ng}$.

\section{Array-CGH}

Array-CGH was performed using the Agilent Human Genome Microarray Kit 44A and 244A (Agilent Technologies, Santa Clara, CA, USA). These are high resolution 60mer oligonucleotide based microarrays containing 44,000 or 244,000 60-mers probes respectively, spanning coding and non-coding genomic sequences with median spacing of $24 \mathrm{~kb}$ and $7.4 \mathrm{~kb}$ respectively.

When using native DNA, both patient and a sex-matched control's DNAs were separately digested with both Alul and Rsal (Promega, Madison, WI, USA) for $2 \mathrm{~h}$ at $37 \mathrm{C}^{\circ}$. Quality of digestion was controlled on a $1 \%$ agarose gel.

When patient and control DNA were amplified digestion was not necessary as the WGA method already generates small fragments, and DNA was directly labelled after purification.

\section{Labelling}

DNA concentration was re-controlled using Qubit quantification method (Invitrogen, Carlsbad, CA, USA) in order to use the same DNA input for the patient and the control labelling. According to the protocol provided by Agilent (Protocol v4.0, June 2006), the native digested or WGA2 amplified DNA were labelled by random priming using the Agilent "Genomic DNA Labelling Kit Plus". Patient DNA and control DNA were labelled with Cy3-dUTP and Cy5-dUTP respectively. Labelled products were purified by Microcon YM-30 filters (Millipore, Billerica, MA, USA). Finally, patient and control DNAs were pooled based on equimolar DNA concentration measured with a Nanodrop ND-1000 spectrophotometer (Nanodrop Technologies, Rockland, Delaware, USA). The mix was denaturated with Human Cot I DNA, and then hybridized on microarrays at $65^{\circ} \mathrm{C}$ for 24 to $48 \mathrm{~h}$ in a hybridization oven with a rotator rack. Washing steps and acetonitrile rinsing were performed according to the Agilent protocol in an ozone free area. Arrays were analysed using the Agilent scanner G2565BA and the Agilent Feature Extraction software version 9.1(CGH-v4_9.1 protocol). The software removed outliers pixels and subtracted local background. 
Normalisation of the data was achieved by linear dye normalisation and log2 ratios of the dye-normalized signals were calculated.

\section{Bioinformatics}

Data were imported into Agilent CGHanalytics software version 3.4.27 for analysis. Identification of probes with a significant gain or loss was based on cut-off values of 0.5 and -1 respectively. Based on CGHanalytics Quality control metrics (QCmetrics), the arrays included had a Derivative Log Ratio (DLR) spread score under 0,320. The DLR Spread metrics estimates the log ratio noise by calculating the spread of log ratio differences between consecutive probes along all chromosomes (Largo, et al., 2007). DNA sequence information from the software was linked to the public UCSC database (Human Genome Browser, May 2004 Assembly: Hg18). We only conserved gains or losses that encompassed at least 3 consecutive spots on the array. We didn't present in the result table the gains and losses corresponding to high frequency copy number variation (CNV).

Based on a quality score for the arrays, we classified them in two groups so that to select arrays that could enter a transversal analysis using the Nexus Copy Number software (www.Biodiscovery.com). Patient CGH files extracted from Feature extraction were uploaded into the Nexus Copy Number software. This software also gives a quality score: all arrays with a score under 0.180 (corresponding to 0.320 in $\mathrm{CGH}$ analytics) allowed the transversal analysis without strong interfering background (that could generate false positive gains or losses). Using this transversal analysis, we compiled all array data and gave a graphic view of the combined results (aggregate) where the frequencies of anomalies were represented by histograms. This aggregate easily pointed out small redundant rearrangements that resulted either from frequent CNV either from one anomaly of the control DNA (mirror image in most of the patients). Finally, all gains or losses could be compared to CNV listed in the database (monthly updated from TCAG) and exported in Tables (Tables 1, 2 and 3) and Figure 1.

The aim of this approach was to detect the redundancy of small regions and get a percentage value to compare with rare CNV frequencies for the same area when such CNV was already described in databases (TCAG human variation website: http://projects.tcag.ca/variation/). 


\section{RESULTS}

\section{Search for CNVs in control DNA}

Male and female control DNAs were co-hybridized on a $244 \mathrm{~K}$ microarray in order to better characterize copy number variants (CNV) that could be present even in these phenotypically normal individuals.

Gains or losses observed in the two control genomic DNA were listed in order to be taken into account in the interpretation of patients' array-CGH results (data not shown).

\section{Array-CGH analysis in patients}

120 patients (70 foetuses and 50 live-born children) were analysed either on a $44 \mathrm{~K}$ or a $244 \mathrm{~K}$ Agilent oligonucleotide arrays.

Out of them, 9 presented with a known deletion already detected by qPCR or QMPSF on known genes (SHH, TGIF, ZIC2 and SIX3) or subtelomeric rearrangements shown by MLPA experiments. They were analysed on 44K arrays.

A first cohort of 37 patients without any karyotypic alterations was also tested with $44 \mathrm{~K}$ agilent array-CGH and another cohort of 74 HPE patients was secondarily tested on $244 \mathrm{~K}$ array-CGH as soon as this platform became commercially available.

\section{Patients with known rearrangements}

Out of the 9 patients with known rearrangements analysed on 44K arrays, 7 were foetuses and 2 were live born children. 7 had severe HPE phenotype with alobar or semilobar form. These patients were known to present deletions in known genes like SHH, TGIF, ZIC2 and SIX3, but array-CGH analysis could give the size of the losses which ranged from 1 gene to $30 \mathrm{Mb}$, and showed that 4 of them had also gain of genomic DNA.

An overview of all imbalances is shown in Table 1.

\section{Patients analysed on $44 \mathrm{~K}$ arrays}

A first array-CGH analysis on 37 HPE patients was performed, using oligonucleotide 44K Agilent ${ }^{\circledR}$ array. 19 cases were foetuses and 18 were live-born children. Sub microscopic chromosomal imbalances were detected in 9 (5 fetuses, 4 children) out 
of them, 6 had an isolated deletions and 3 had duplications. The size of the imbalances ranged from $50 \mathrm{~Kb}$ to $16.9 \mathrm{Mb}$. (Table 2)

\section{Patients analysed on 244K arrays}

Another cohort of 74 HPE (45 foetuses and 29 live-born children) was then analysed, using a higher resolution array (244K Agilent®).

19 patients (12 fetuses, 7 children) out of 74 (26\%) presented copy number variations not described in the CNV databases. These rearrangements are more frequently deletions as 12 patients had an isolated or associated loss. 11 patients had isolated or associated duplications. The size's range of the imbalances is very large, from 300 $\mathrm{Kb}$ to $16.5 \mathrm{Mb}$ (Table 3).

\section{Nexus study}

Compiling 90 arrays (quality score below 0,180) in the Nexus study, the aggregate pointed out 2 regions overlapping known CNV but with a higher recurrence than what was reported in CNV databases. The first locus included two genes: MACROD2 and FLRT3 in 20p12.1. The second one included the gene TPPP in 5p15.3.

\section{DISCUSSION}

This study is the first series of HPE patients to be screened for chromosomal imbalances with high resolution oligonucleotide microarrays. In a total of 111 patients with normal karyotype, 28 were detected with chromosomal imbalances (25\%). This unexpected high frequency, whatever the size, location and redundancy of the rearrangements, demonstrates that $\mathrm{CGH}$ is mandatory to detect submicroscopic molecular defects; consequently, adding these anomalies to the results of the classic diagnosis screening of isolated HPE, the rate of identified molecular defects could exceed for the first time $50 \%$ of cases.

\section{Methodology}

\section{Control DNA}

We decided to use genomic DNA from one normal male 46,XY and one normal female $46, X X$ as controls. Indeed, it seemed to us that it was easier to validate the CNVs status of these two DNA samples and thus avoid false positive or negative results in our series. A similar strategy was chosen by Carter et al (Carter, 2007), 
who selected NA15510, the source of fosmid library used to confirm genome assembly during the finishing of the human genome, and NA10851, a well characterized cell line DNA from the Hap-Map collection.

\section{CNV interference}

Results need to take into account the presence of potential copy number variants (CNV) present in the normal human genome. Indeed, the recent appreciation of widespread copy number variation in genomes of healthy subjects was a significant challenge for teams that wished to use array-CGH in order to correlate chromosomal imbalances and diagnosis of constitutional disorders. Public available databases that accumulate CNV data on hundreds of healthy individuals are now available. So we systematically compared our results to the Database of Genomic Variants (DGV) (http://projects.tcag.ca/variations), which in June 2008 contained 17641 CNVs entries from 49 different published studies using different array platforms and healthy human groups; most of these CNVs range from 40 to $100 \mathrm{~kb}$ (Carter, 2007). The referenced CNVs could account for over $20 \%$ of the human genome. Of course, this database should be considered with great caution, especially when these CNVs are reported only in a single individual out of hundreds what should definitely not deny any morbid role for such locus. Every month, new CNV data are described in the literature, so it is very difficult to consider all these data and to appreciate their accuracy. In our Nexus study, we pointed out two loci of interest based on a higher frequency than what could be found in CNV database:

A first chromosomal region presented 4 gains and 5 losses in HPE patients, covering mostly $150 \mathrm{~Kb}$, in $5 \mathrm{p} 15.3$. This redundant rearranged region contains a candidate gene, TPPP, expressed in adult brain and often described in Alzheimer papers.

A second one was located in 20p. Indeed, among 110 HPE patients, 4 presented rearrangement at 20p12.1, 3 losses and 1 gain. These rearrangements spanned over several closed regions, all concerning one or several exons of MACROD2 gene (C20orf133) (Figure 1) whose embryonic expression pattern in the mouse orthologue is compatible with a role in holoprosencephaly (Maas, et al., 2007). This gene contains a nested gene in its third exon, called FLRT3, coding a fibronectin leucinrich repeat transmembrane protein, which could be a conserved Nodal target. Indeed, loss of function in the FLRT3 gene leads to defects in ventral closure, headfold fusion and definitive endoderm migration (Maretto, et al., 2008). 
A deletion of MACROD2 was previously found in one patient with Kabuki syndrome (KS) ; sequencing of 19 other KS patients did not reveal any mutation in MACROD2 discarding this gene as a unique candidate gene for KS (Maas, et al., 2007).

To confirm that the rearrangements observed in our 4 patients were not benign CNV, the different database reporting these large-scale polymorphisms were investigated and unlike the Maas paper data, we could determine that they overlapped described CNVs. Moreover, Kuniba et al recently described the results of a deletion assay for the exon 5 in MACROD2 and a mutation analysis of MACROD2 and FLRT3 among 43 patients with KS in Japan (Kuniba, et al., 2008). They also showed that 2 patients out of 18 presented copy number variations in this region, and concluded that MACROD2 and/or FLRT3 could not be the causative gene in most Japanese KS patients.

These two papers and our own analysis demonstrate that one should be very cautious about the involvement of genes in diseases without an achieved CNV database to analyze the results.

\section{Minimal size to be considered}

Currently available data suggest using a DNA size cut-off for a positive result. To avoid listing many anomalies (small CNV or background noise related to one or two consecutive spots on the array), we chose that all data presented in tables must result from three consecutive co-deleted or co-duplicated probes on the $44 \mathrm{~K}$ or $244 \mathrm{~K}$ arrays to produce strong evidence of any genomic defect; consequently their respective resolution can be estimated to $48 \mathrm{~kb}$ and $14.8 \mathrm{~kb}$ respectively.

This compromise is not perfect as this cut-off of 3 spots on the $44 \mathrm{~K}$ array would have led us to discard a deletion located only on SIX3 gene (Table 1) and involving only one spot, if we had not been aware of its existence based on previous specific studies (Bendavid, et al., 2006a).

\section{Impact of array resolution}

We used the oligonucleotide $44 \mathrm{~K}$ Agilent ${ }^{\circledR}$ arrays to test 37 HPE patients (19 foetuses and 18 live-born children). Sub microscopic chromosomal imbalances were detected in 9 out of them (24\%), 6 deletions and 4 duplications (Table 2). Another 
cohort of 74 HPE (45 foetuses and 29 live-born children) was then analysed, using $244 \mathrm{~K}$ Agilent@ arrays. 19 patients out of 74 (26\%) presented rearrangements.

When using the high resolution arrays, the rate of detected rearrangements modestly raises (26\% versus $24 \%$ ). This suggests that the resolution of the $44 \mathrm{~K}$ arrays could be sufficient for routine screening of HPE patients. On the opposite, the higher rate of small deletions detected by $244 \mathrm{~K}$ needs more data compiling (based on Nexus software to point out the more frequent anomalies and exclude putative CNV). In routine diagnosis, the cost of the $244 \mathrm{~K}$ array versus its modest raise of the detection rate could certainly limit the $\mathrm{CGH}$ approach to the $44 \mathrm{~K}$ array.

\section{Patient's results}

Identified loci were heterogeneous in size and poorly redundant, but
large anomalies were preferentially found in fetuses

Previous data suggested that deletions in known genes (SHH, SIX3, ZIC2 and TGIF) were more frequent in foetuses than in children, who, on the opposite, presented a higher rate of mutations (Bendavid, et al., 2006a; Bendavid, et al., 2006b). The present study corroborates this hypothesis as 17 chromosomal rearrangements were observed in foetuses (61\%) versus 11 in children (39\%).

The structural variations observed in our cohort present a wide range of sizes.

We first determined the precise size of rearrangements in samples known to be deleted for HPE genes (SHH, TGIF, SIX3 and ZIC2) by qPCR, QMPSF or MLPA or by high resolution karyotype (Table 1$)$. The patient $\left(\mathrm{N}^{\circ} 8\right)$ with a deletion of TGIF in $18 \mathrm{p}$ shown by quantitative PCR (Bendavid, et al., 2006a) had in fact a $10 \mathrm{Mb}$ loss of telomeric genomic DNA. Deletions in $13 q$ including ZIC2 ranged from $1.7 \mathrm{Mb}$ to 30.7 $\mathrm{Mb}$, while those including $\mathrm{SHH}$ in $7 \mathrm{q}$ ranged from $3 \mathrm{Mb}$ to $7 \mathrm{Mb}$. The severity of the phenotype seems to be correlated with the size of the deletion, if we consider that wider rearrangements are mostly found in foetuses with alobar or semi-lobar HPE, while the smaller ones (even concerning a single probe like the patient $\left(N^{\circ} 1\right)$ with isolated $S I X 3$ deletion) were preferentially observed in live-born children, with lobar HPE accompanied with minor signs. Nevertheless, phenotype/genotype correlation is not straight as children with typical HPE do not have a higher rate of rearrangements than children with minor signs. 


\section{Parental analysis}

In our series, out of 28 patients with gains or losses, both parents could be tested in 21 cases (focusing on 26 rearrangements). The aim of this parental analysis was to further modulate the role of these rearrangements in phenotype onset based on their inheritance.

Therefore, we postulated first that all anomalies found isolated (not associated with a mutation) and that raised de novo in the proband would be the more likely to be involved in the phenotype. Second, all anomalies found isolated but inherited from one parent would be part from a genetic background and may only act with a variable penetrance or with an associated factor. Finally, if found associated with a mutation and inherited from one parent, the anomaly would more likely be a very minor modulator.

In our series, 9 patients had at least one gain or loss inherited from one parent; 8 were duplications whereas only 3 were deletions (patients $N^{\circ} 23,30$ and 32 ). In 6 patients $\left(\mathrm{N}^{\circ} 18,21,27,30,32\right.$ and 37$)$, rearrangements were associated to mutations. Therefore, no definitive conclusion about the involvement of these different regions can be given.

On the opposite, out of the 11 patients with de novo gains or losses, we had 9 deletions and only 4 duplications. 8 involved known HPE loci: $2 p$ (SIX3), 7qter (SHH), 13q (ZIC2), 18pter (TGIF), 20pter and 21qter. This reinforces the implication of loci like 20pter or 21qter in HPE but also gives new candidate loci with regions not previously involved in the disease: 1q, 6q, 7p, 10q, 14q and 17q. The 14q del was already reported by Kamnasaran et al in 2005 as a putative HPE loci (Kamnasaran, et al., 2005). The two overlapping $6 q$ del are also particularly interesting as they mapped a new locus that appeared twice de novo.

It's worth noting that one patient ( $\mathrm{N}^{\circ 25}$ ) presents a SHH locus duplication. This could be associated with a $\mathrm{SHH}$ gain of function, what has never been described before in HPE. Nevertheless, this defect was also found in the mother (normal phenotype). $\mathrm{SHH}$ gains of function are usually associated with basocellular carcinoma that have not been described to date in this family. On another hand, this rearrangement may cause a SHH loss of function based on the modification of the chromatin environment. Further investigations on $\mathrm{SHH}$ expression in this family should be overtaken. 


\section{Update of HPE loci map}

The major aim of our research is to identify candidate regions, map them (Figure 2) and thus extract new HPE candidate genes. Because of the large number of non redundant loci found and the large number of genes covered, it was not relevant to list every candidate gene that could be hypothesized out of these regions. Nevertheless, our results are a milestone in further genetic research and diagnosis in HPE. Effectively, an important bioinformatics investigation on these regions can therefore be performed, based on gene networks and known functional studies results in order to prioritize the best candidate regions and genes out of our data.

Today, only one region could be easily hypothesized as it showed a redundancy in 4 patients who presented a deletion of about $100 \mathrm{~Kb}$ without overlap with CNVs in the TCAG database to date. This region is located in 10p12.1 and contains a candidate gene, PATCHED3, belonging to the PATCHED family, receptor of $\mathrm{SHH}$, one of the main HPE genes. Nevertheless, we could investigate the parents for one case ( $\left.{ }^{\circ} 30\right)$ and the deletion was inherited from the father, knowing that furthermore the father also transmitted a $\mathrm{SHH}$ mutation. Another case $\left(\mathrm{N}^{\circ 27}\right)$ with no parental study also had an associated SHH mutation. Consequently, a role for PATCHED3 is questionable and it's difficult to consider it as a strong modulator making the fetus phenotype worse than his father's.

\section{CGH use in routine diagnosis}

For diagnosis, this study demonstrates that the CGHarray approach must be another part of the molecular routine so that to get as much potential markers of the disease as possible to help the genetic counseling. In our experience, this method has been very helpful in the identification of unbalanced subtelomeric anomalies (as MLPA for subtelomeres but with the advantage of determining the breakpoints in the same time) and led to identification of parental cryptic balanced translocations by FISH.

Finally, this study also reinforces the multi-hit hypothesis showing 16 patients with associated gains and losses or rearrangements and mutations. The patients (with severe phenotype) with known mutations inherited from one parent (with mild phenotype) plus a gain and/or a loss are a strong example of what could be considered as a genetic background helping the mutation penetrance. 


\section{Conclusion}

This is the first study screening a large cohort of isolated HPE by CGHarray. Results demonstrated a high frequency of submicroscopic anomalies with yield of $25 \%$. These anomalies are heterogeneous in size and poorly redundant, what give even more evidence of the multi and plurigenic origin of this developmental disorder. The map of these anomalies added to known candidate loci will certainly help to associate potential candidate genes from developmental research with the human disease. This study also demonstrates that CGH must be part of the molecular diagnosis algorithm to help clinicians to get more disease markers for the difficult HPE genetic counseling.

\section{Databases}

Database of Genomic Variants (http://projects.tcag.ca/variations), Human Genome Browser, (May 2004 Assembly: Hg18).

Nexus Copy Number software (www.Biodiscovery.com)

\section{BIBLIOGRAPHY}

Belloni E, Muenke M, Roessler E, Traverso G, Siegel-Bartelt J, Frumkin A, Mitchell HF, Donis-Keller H, Helms C, Hing AV, Heng HH, Koop B, Martindale D, Rommens JM, Tsui LC, Scherer SW. 1996. Identification of Sonic hedgehog as a candidate gene responsible for holoprosencephaly. Nat Genet 14(3):353-6.

Bendavid C, Dubourg C, Gicquel I, Pasquier L, Saugier-Veber P, Durou MR, Jaillard S, Frebourg T, Haddad BR, Henry C, Odent S, David V. 2006a. Molecular evaluation of foetuses with holoprosencephaly shows high incidence of microdeletions in the HPE genes. Hum Genet 119(1-2):1-8.

Bendavid C, Dubourg C, Pasquier L, Gicquel I, Le Gallou S, Mottier S, Durou MR, Henry C, Odent S, David V. 2007. MLPA screening reveals novel subtelomeric rearrangements in holoprosencephaly. Hum Mutat 28(12):1189-97.

Bendavid C, Haddad BR, Griffin A, Huizing M, Dubourg C, Gicquel I, Cavalli LR, Pasquier L, Shanske AL, Long R, Ouspenskaia M, Odent S, Lacbawan F, David V, Muenke M. 2006b. Multicolor FISH and quantitative PCR can detect submicroscopic deletions in holoprosencephaly patients with a normal karyotype. J Med Genet.

Brown SA, Warburton D, Brown LY, Yu CY, Roeder ER, Stengel-Rutkowski S, Hennekam RC, Muenke M. 1998. Holoprosencephaly due to mutations in ZIC2, a homologue of Drosophila odd-paired. Nat Genet 20(2):180-3.

Carter NP. 2007. Methods and strategies for analyzing copy number variation using DNA microarrays. Nat Genet 39(7 Suppl):S16-21.

Cohen MM, Jr. 2006. Holoprosencephaly: clinical, anatomic, and molecular dimensions. Birth Defects Res A Clin Mol Teratol 76(9):658-73. 
de la Cruz JM, Bamford RN, Burdine RD, Roessler E, Barkovich AJ, Donnai D, Schier AF, Muenke M. 2002. A loss-of-function mutation in the CFC domain of TDGF1 is associated with human forebrain defects. Hum Genet 110(5):422-8.

Dubourg C, Bendavid C, Pasquier L, Henry C, Odent S, David V. 2007. Holoprosencephaly. Orphanet J Rare Dis 2:8.

Dubourg C, Lazaro L, Pasquier L, Bendavid C, Blayau M, Le Duff F, Durou MR, Odent S, David V. 2004. Molecular screening of SHH, ZIC2, SIX3, and TGIF genes in patients with features of holoprosencephaly spectrum: Mutation review and genotype-phenotype correlations. Hum Mutat 24(1):43-51.

Edison RJ, Berg K, Remaley A, Kelley R, Rotimi C, Stevenson RE, Muenke M. 2007. Adverse birth outcome among mothers with low serum cholesterol. Pediatrics 120(4):723-33.

Gripp KW, Wotton D, Edwards MC, Roessler E, Ades L, Meinecke P, Richieri-Costa A, Zackai EH, Massague J, Muenke M, Elledge SJ. 2000. Mutations in TGIF cause holoprosencephaly and link NODAL signalling to human neural axis determination. Nat Genet 25(2):205-8.

Hogervorst FB, Nederlof PM, Gille JJ, McElgunn CJ, Grippeling M, Pruntel R, Regnerus R, van Welsem T, van Spaendonk R, Menko FH, Kluijt I, Dommering C, Verhoef S, Schouten JP, van't Veer LJ, Pals G. 2003. Large genomic deletions and duplications in the BRCA1 gene identified by a novel quantitative method. Cancer Res 63(7):1449-53.

Kamnasaran D, Chen CP, Devriendt K, Mehta L, Cox DW. 2005. Defining a holoprosencephaly locus on human chromosome $14 q 13$ and characterization of potential candidate genes. Genomics 85(5):608-21.

Kuniba H, Tsuda M, Nakashima M, Miura S, Miyake N, Kondoh T, Matsumoto T, Moriuchi H, Ohashi $\mathrm{H}$, Kurosawa K, Tonoki H, Nagai T, Okamoto N, Kato M, Fukushima Y, Naritomi K, Matsumoto N, Kinoshita A, Yoshiura KI, Niikawa N. 2008. Lack of C20orf133 and FLRT3 mutations in 43 patients with Kabuki syndrome in Japan. J Med Genet 45(7):479-80.

Largo C, Saez B, Alvarez S, Suela J, Ferreira B, Blesa D, Prosper F, Calasanz MJ, Cigudosa JC. 2007. Multiple myeloma primary cells show a highly rearranged unbalanced genome with amplifications and homozygous deletions irrespective of the presence of immunoglobulinrelated chromosome translocations. Haematologica 92(6):795-802.

Maas NM, Van de Putte T, Melotte C, Francis A, Schrander-Stumpel CT, Sanlaville D, Genevieve D, Lyonnet S, Dimitrov B, Devriendt K, Fryns JP, Vermeesch JR. 2007. The C20orf133 gene is disrupted in a patient with Kabuki syndrome. J Med Genet 44(9):562-9.

Maretto S, Muller PS, Aricescu AR, Cho KW, Bikoff EK, Robertson EJ. 2008. Ventral closure, headfold fusion and definitive endoderm migration defects in mouse embryos lacking the fibronectin leucine-rich transmembrane protein FLRT3. Dev Biol 318(1):184-93.

Ming JE, Muenke M. 2002. Multiple hits during early embryonic development: digenic diseases and holoprosencephaly. Am J Hum Genet 71(5):1017-32.

Ouspenskaia MV, Karkera JP, Roessler E, Shen MM, Goldmunts E, Bowers P, Towbin J, Belmont J, Muenke M. Role of FAST1 gene in the development of holoprosencephaly (HPE) and congenital cardiac malformations in humans; 2002 Oct 2002; Baltimore, USA. American Society of Human Genetics. $p N^{\circ} 822$.

Roessler E, Belloni E, Gaudenz K, Jay P, Berta P, Scherer SW, Tsui LC, Muenke M. 1996. Mutations in the human Sonic Hedgehog gene cause holoprosencephaly. Nat Genet 14(3):357-60.

Roessler E, Muenke M. 1998. Holoprosencephaly: a paradigm for the complex genetics of brain development. J Inherit Metab Dis 21(5):481-97.

Roessler E, Muenke M. 2003. How a Hedgehog might see holoprosencephaly. Hum Mol Genet 12 Spec No 1:R15-25.

Wallis DE, Muenke M. 1999. Molecular mechanisms of holoprosencephaly. Mol Genet Metab 68(2):126-38. 
Figure 1: Schematic view of the exons and introns of MACROD2 and FLRT3 genes. MACROD2 contains 17 exons and is 2057697 bp size. It contains in the third intron the FLRT3 gene. This three exons gene is 13628 bp in size. Red lines indicate deletion of patients, Green line indicate duplication. Positions of CNVs are represented by pink lines (updated in june 2008).

Figure 2: This figure represents all chromosome ideograms with: 1) in yellow, on the left of each ideogram, all related known HPE loci included in Roessler et al (1998) and 14q loci from Kamnasaran and al (2005) papers. 2) in green all gains found in our cohort 3) in red all losses found in our cohort. Gains and losses are associated with the patient numbers that can be found in tables 2, 3 and 4 . 


\section{Page 19 of 24}

Human Mutation

1

2

3

4

5

6

7

8

9

10

11

12

13

14

15

16

17

18

19

20

21

22

23

24

25

26

27

28

29

30

31

32

33

34

35

36

37

38

39

40

41

42

43

44

45

46

47

48

49

50

51

52

53

54

55

56

57

58

59

60

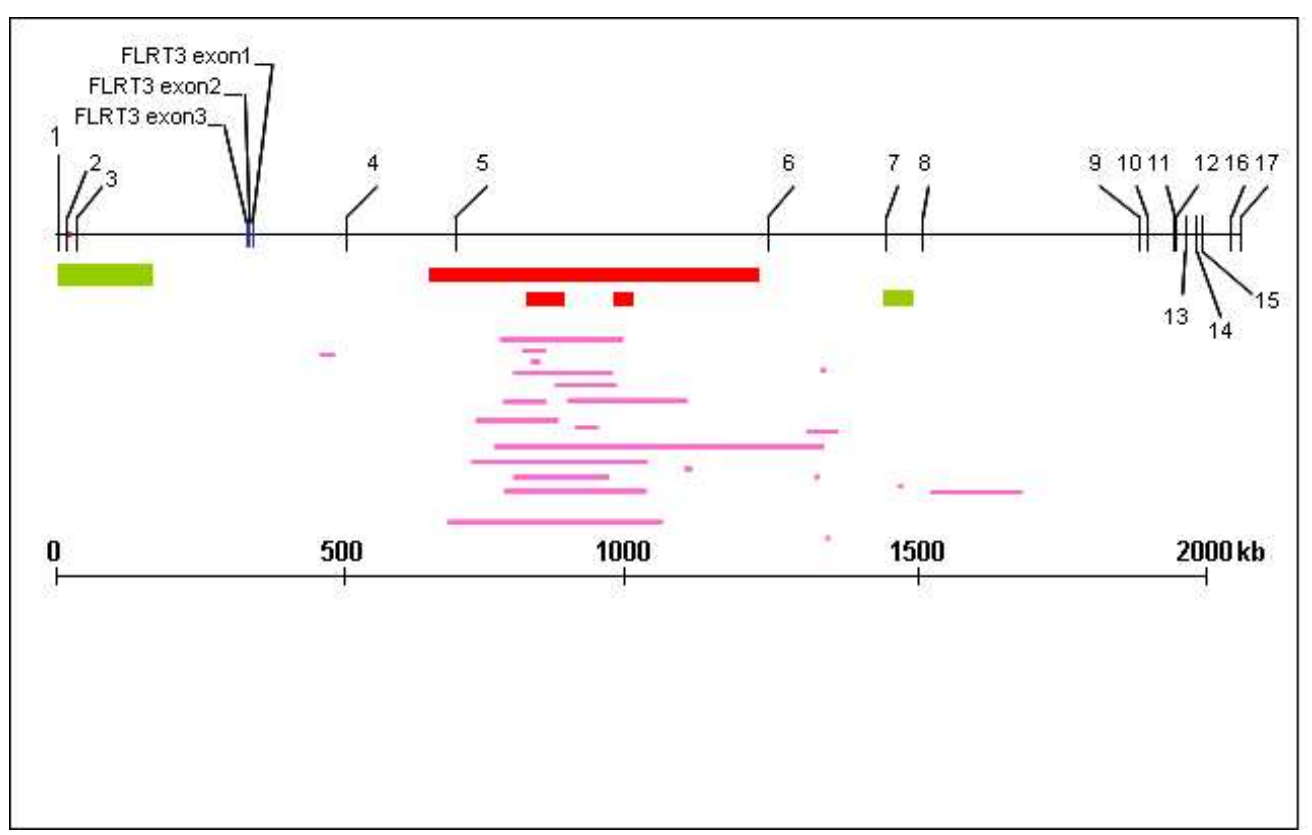

: Schematic view of the exons and introns of MACROD2 and FLRT3 genes. MACROD2 contains 17 exons and is 2057697 bp size. It contains in the third intron the FLRT3 gene. This three exons gene is 13628 bp in size. Red lines indicate deletion of patients, Green line indicate duplication. Positions of CNVs are represented by pink lines (updated in june 2008). $170 \times 106 \mathrm{~mm}$ ( $96 \times 96 \mathrm{DPI})$

John Wiley \& Sons, Inc. 


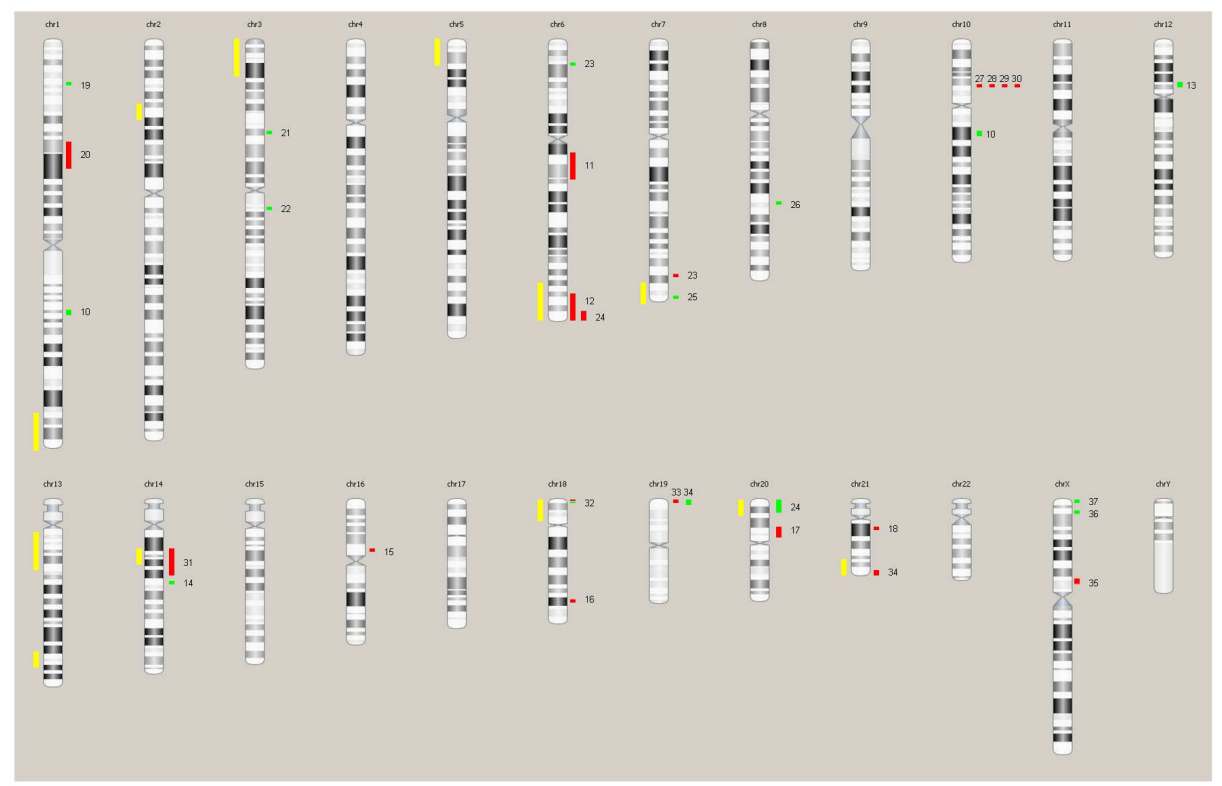

This figure represents all chromosome ideograms with: 1) in yellow, on the left of each ideogram, all related known HPE loci included in Roessler et al (1998) and 14q loci from Kamnasaran and al (2005) papers. 2) in green all gains found in our cohort 3) in red all losses found in our cohort. Gains and losses are associated with the patient numbers that can be found in tables 2, 3 and 4. 
Table 1: CGH analysis in 9 patients with known defects

\begin{tabular}{|c|c|c|c|c|c|c|c|}
\hline Patient & Phenotype & $\mathrm{F} / \mathrm{C}$ & Sexe & Anomalies & Start-End & size $(M b)$ & sequencing \\
\hline 1 & lobar & C & & Del $2 p$ & $45022541-45025894$ & $\begin{array}{l}\text { Only six3 } \\
\text { gene }\end{array}$ & \\
\hline \multirow[t]{2}{*}{2} & \multirow[t]{2}{*}{ lobar } & \multirow[t]{2}{*}{ C } & \multirow[t]{2}{*}{ M } & Del 5qter & 177354922-ter & 3,5 & \\
\hline & & & & Dup $17 q$ & 70880633-ter & 7,9 & \\
\hline \multirow[t]{2}{*}{3} & \multirow[t]{2}{*}{ alobar } & \multirow[t]{2}{*}{$\mathrm{F}$} & & Dup 7pter & $0-6167900$ & 7 & \\
\hline & & & & Del 7qter & 152087784-ter & 7 & \\
\hline \multirow[t]{2}{*}{4} & \multirow[t]{2}{*}{ semi lobar } & \multirow[t]{2}{*}{$\mathrm{F}$} & \multirow[t]{2}{*}{$\mathrm{F}$} & Del $7 q$ & $\begin{array}{r}154943585- \\
1578473434 \\
\end{array}$ & 3 & \\
\hline & & & & Dup $8 p$ & $0-409876$ & 0.4 & \\
\hline 5 & syndromic HPE & $\mathrm{F}$ & $\mathrm{F}$ & Del 7qter & 152232455-ter & 6,2 & \\
\hline 6 & semi lobar & $\mathrm{F}$ & $\mathrm{M}$ & Del 13q & $98323528-100026969$ & 1,7 & \\
\hline 7 & alobar & $\mathrm{F}$ & $\mathrm{M}$ & Del $13 q$ ter & 83266096-ter & 30,7 & \\
\hline 8 & semi lobar & $\mathrm{F}$ & $\mathrm{M}$ & Del 18pter & 66272268-ter & 10 & \\
\hline \multirow[t]{2}{*}{9} & \multirow{2}{*}{$\begin{array}{c}\text { alobar } \\
\text { cardiac anomalies }\end{array}$} & \multirow[t]{2}{*}{$\mathrm{F}$} & \multirow[t]{2}{*}{$M$} & Del 20p & $0-8268492$ & 8,2 & \\
\hline & & & & Dup 21q & 35804023-ter & 11 & \\
\hline
\end{tabular}


Table 2: Summary of copy number changes detected by 44K array CGH (short clinical description and associated mutations in HPE genes)

\begin{tabular}{|c|c|c|c|c|c|c|c|}
\hline Patient & Phenotype & $\mathrm{F} / \mathrm{C}$ & Sexe & Anomalies & Start-End & taille $(\mathrm{Mb})$ & sequencing \\
\hline \multirow[t]{2}{*}{10} & \multirow[t]{2}{*}{ semi lobar } & \multirow[t]{2}{*}{$\mathrm{F}$} & \multirow[t]{2}{*}{$\mathrm{F}$} & Dup 1q & $165319168-165662668$ & 0,3 & \\
\hline & & & & Dup $10 q$ & $59312961-60086986$ & 0,8 & \\
\hline 11 & minor signs & $\mathrm{C}$ & $\mathrm{M}$ & Del $6 q$ & 69637936-86100038 & 16,9 & \\
\hline 12 & Semi lobar & $\mathrm{F}$ & $\mathrm{F}$ & Del $6 q$ & 155166802-ter & 15,7 & \\
\hline 13 & semi lobar & $\mathrm{C}$ & $\mathrm{M}$ & Dup 12p & $26727022-27427780$ & 0,8 & \\
\hline 14 & lobar, polymalformations & $\mathrm{F}$ & $\mathrm{M}$ & Dup14q & $49150663-49200220$ & 0,05 & \\
\hline 15 & syndromic HPE & C & $\mathrm{F}$ & Del $16 p$ & $29407325-30255748$ & 0,85 & \\
\hline 16 & semi lobar & $\mathrm{F}$ & $\mathrm{M}$ & Del $18 q$ & $62405035-63364892$ & 1 & \\
\hline 17 & alobar & $\mathrm{F}$ & $\mathrm{F}$ & Del 20p & $18377837-23793823$ & 5,4 & \\
\hline 18 & semi lobar & $\mathrm{C}$ & $\mathrm{F}$ & Del 21q & $19024763-20666763$ & 1,6 & Zic2 de novo \\
\hline
\end{tabular}


Table 3: Summary of copy number changes detected by 244K array CGH (short clinical description and associated mutations in HPE genes)

\begin{tabular}{|c|c|c|c|c|c|c|c|}
\hline Patient & Phenotype & $\mathrm{F} / \mathrm{C}$ & Sexe & Anomalies & Start-End & Size (Mb) & sequencing \\
\hline 19 & lobar & C & M & Dup 1p & $26866731-27930229$ & 1,06 & \\
\hline 20 & minor signs & C & $\mathrm{F}$ & Del 1p & $61656706-77968936$ & 16,4 & \\
\hline 21 & semi lobar & $\mathrm{F}$ & $M$ & Dup 3p & $54969531-55519135$ & 0,55 & SHH paternal \\
\hline 22 & alobar & $\mathrm{F}$ & $\mathrm{F}$ & Dup3q & $101837302-101896892$ & 0,6 & \\
\hline \multirow[t]{2}{*}{23} & \multirow[t]{2}{*}{ minor signs } & \multirow[t]{2}{*}{ C } & \multirow[t]{2}{*}{$\mathrm{F}$} & Del 7q & $142530842-142603299$ & 0,7 & \\
\hline & & & & Dup 6p & $13251543-13558381$ & 0,3 & \\
\hline \multirow[t]{2}{*}{24} & \multirow[t]{2}{*}{ minor signs } & \multirow[t]{2}{*}{ C } & \multirow[t]{2}{*}{ M } & Del 6qter & 165767853-ter & 5,2 & \\
\hline & & & & Dup 20pter & $0-7967454$ & 8 & \\
\hline 25 & semi lobar & $\mathrm{F}$ & $M$ & Dup $7 q$ & $154623987-155557785$ & 0,93 & \\
\hline 26 & minor signs & $\mathrm{C}$ & $\mathrm{F}$ & Dup $8 q$ & $98220486-98365015$ & 0,15 & \\
\hline 27 & minor signs & C & M & Del 10p & $27656534-27753830$ & 0,10 & $\mathrm{SHH}$ \\
\hline 28 & lobar & $\mathrm{F}$ & $M$ & Del 10p & $27645595-27754606$ & 0,11 & \\
\hline 29 & alobar & $\mathrm{F}$ & $\mathrm{F}$ & Del 10p & $27645595-27754606$ & 0,11 & \\
\hline 30 & lobar + familial form & $\mathrm{F}$ & M & Del 10p & $27645595-27754606$ & 0,11 & SHH paternal \\
\hline 31 & alobar & $\mathrm{F}$ & $\mathrm{F}$ & Del $14 q$ & $29960612-46532138$ & 16,5 & \\
\hline \multirow[t]{2}{*}{32} & \multirow[t]{2}{*}{ alobar } & \multirow[t]{2}{*}{$\mathrm{F}$} & \multirow[t]{2}{*}{ M } & Del $18 p$ & $0-602022$ & 0,6 & \\
\hline & & & & Dup 18p & $1707459-1834111$ & 0,13 & Zic2 (de novo) \\
\hline 33 & semi lobar & $\mathrm{F}$ & $M$ & Del $19 p$ & $0-402006$ & 0,4 & \\
\hline \multirow[t]{2}{*}{34} & \multirow[t]{2}{*}{ minor signs } & \multirow[t]{2}{*}{ C } & \multirow[t]{2}{*}{$\mathrm{F}$} & Dup 19p & $0-1124473$ & 1,1 & \\
\hline & & & & Del 21q & 44012487-ter & 2,9 & \\
\hline 35 & semi lobar & $\mathrm{F}$ & $\mathrm{F}$ & Del Xp & $48145179-52507792$ & 4,4 & \\
\hline 36 & minor signs & $\mathrm{F}$ & $\mathrm{F}$ & DupXp & $7542546-8091810$ & 0,5 & \\
\hline 37 & alobar & $\mathrm{F}$ & M & Dup Xp & $2709755-2923910$ & 0,3 & 2 in Zic2 \\
\hline
\end{tabular}


Table 4:Study of inheritance in 21 probands (out of 31) whose both parents were available for analysis. Gene dosage was performed (QMPSF or MLPA or CGH) in the parents to check if the remaniement was inherited. Out of three patients with subtelomeric gain and loss, FISH was only performed in one case and confirmed a balanced translocation in one parent.

\begin{tabular}{|c|c|l|l|l|l|}
\cline { 2 - 5 } \multicolumn{2}{c|}{} & \multicolumn{2}{c|}{ mutations } & \multicolumn{2}{c|}{ remaniement } \\
\hline Patient & anomalies & father & mother & father & mother \\
\hline 10 & Dup $1 q$ & No & No & No & No \\
\cline { 2 - 6 } & Dup 10q & No & No & No & No \\
\hline 1 & Del $2 p$ & No & No & No & No \\
\hline 21 & Dup $3 p$ & Yes & no & Yes & No \\
\hline 22 & Dup3q & No & No & Yes & No \\
\hline 23 & Dup 6p & No & No & No & Yes \\
\cline { 2 - 6 } & Del 7q & No & No & No & Yes \\
\hline 11 & Del 6q & No & No & No & No \\
\hline 12 & Del 6q & No & No & No & No \\
\hline 3 & Del 7qter & No & No & No & balanced \\
\cline { 2 - 6 } & Dup 7pter & No & No & No & balanced \\
\hline 25 & Dup 7q & No & No & No & Yes \\
\hline 26 & Dup $8 q$ & No & No & No & Yes \\
\hline 30 & Del 10p & Yes & No & Yes & No \\
\hline 13 & Dup 12p & No & No & Yes & No \\
\hline 6 & Del 13q & No & No & No & No \\
\hline 7 & Del 13q ter & No & No & No & No \\
\hline 31 & Del 14q & No & No & No & No \\
\hline 2 & Dup 17q & No & No & No & No \\
\hline 32 & Del 18p & No & No & Yes & No \\
\cline { 2 - 5 } & Dup 18p & No & No & Yes & No \\
\hline 8 & Del 18pter & No & No & No & No \\
\hline 9 & Del 20p & No & No & No & No \\
\cline { 2 - 5 } & Dup 21q & No & No & No & No \\
\hline 18 & Del 21q & No & No & No & No \\
\hline 36 & DupXp & No & No & Yes & No \\
\hline
\end{tabular}

